\title{
Sistem Pakar Penentuan Penempatan Karyawan Terhadap Bidang Pekerjaan Berbasis Web Dengan Metode Case Based Reasoning Studi Kasus CV.Mitra Tehnik
}

\author{
Yuda Febri Astrawinata'1, Joko Triono2, Pradityo Utomo 3 \\ 1,2,3Manajemen Informatika , Universitas Merdeka Madiun, Madiun, Indonesia \\ Email: 1yudhaastrawinata@gmail.com, 2jokotriono2015@gmail.com, 3pradityou@gmail.com
}

\begin{abstract}
Abstrak
Banyak hal yang dapat dilakukan dikarenakan pesatnya perkembangan teknologi dan informasi, salah satu hal yang dapat dilakukan adalah menentukan penempatan karyawan dengan bidang pekerjaan, salah satu cara yang mudah untuk menentukan penempatan karyawan dengan bidang pekerjaan adalah dengan menggunakan sistem pakar. Sistem pakar ini dibuat untuk dimanfaatkan oleh perusahaan dalam menentukan penempatan karyawan dengan bidang pekerjaan. Pembangunan aplikasi sistem pakar ini menggunakan metode pengembangan sistem pakar dan bahasa pemrograman yang digunakan PHP, sedangkan untuk database menggunakan MySQL. Teknik pengumpulan data dilakukan dengan cara melakukan wawancara dengan perusahaan terkait dan browsing di internet. metode inferensi yang digunakan dalam pembangunan sistem pakar ini adalah metode case based reasoning yaitu metode yang mengambil hasil kesimpulan kasus baru berdasarkan kasus lama dan memberikan solusi pada kasus baru berdasrkan kasus lama yang memiliki nilai kemiripan tertinggi. Aplikasi telah berhasil dibangun dan diuji dengan metode pengujian black box dengan tingkat keberhasilan $100 \%$.
\end{abstract}

Kata Kunci: Sistem pakar, php, mysql, case based reasoning, cbr, penempatan karyawan

\section{PENDAHULUAN}

Penempatan yang tepat merupakan hal yang penting bagi kehidupan contohnya penempatan karyawan pada suatu bidang pekerjaan di sebuah perusahaan, penempatan karyawan pada bidang yang tepat merupakan suatu hal yang sangat penting sebab apabila perusahaan tersebut menempatkan karyawan yang tidak sesuai dengan bidangnya maka potensi karyawan tersebut menjadi tidak maksimal yang nantinya akan berdampak pada kinerja tim pada bidang tersebut. 
Suatu perusahaan dengan manajemen yang baik biasanya memiliki beberapa bidang yang bekerja untuk tugas nya masing-masing. Untuk bekerja pada bidang yang cocok, karyawan harus memenuhi beberapa syarat atau kriteria yang dimiliki bidang tersebut. Karyawan yang bekerja pada bidang yang tidak cocok dapat membuat pekerjaan tidak dapat dilakukan secara maksimal.

Untuk membantu CV.Mitra Tehnik dalam menempatkan karyawan yang sesuai dengan bidang pekerjaan dibuatlah sebuah sistem pakar. Sistem pakar sendiri adalah sebuah sistem komputer cerdas yang menggunakan pengetahuan dan prosedur inferensi untuk menyelesaikan masalah yang cukup sulit sehingga apabila tidak menggunakan sistem maka membutuhkan seorang ahli untuk menyelesaikannya [1].

Sejalan dengan perkembangan kecerdasan buatan, sistem pakar juga ikut berkembang. Pembuatan sistem pakar dapat dilakukan dengan banyak metode, salah satunya yaitu metode Case-Based Reasoning(CBR). Secara umum, CaseBased Reasoning (CBR) merupakan suatu konsep penalaran dalam pemecahan masalah melalui catatan penanganan kasus yang pernah dilakukan oleh seorang ahli [2]. Adapun alasan mengapa penulis menggunakan metode Case Based Reasoning yaitu metode ini menggunakan informasi/data yang sudah ada untuk menyelesaikan masalah (Malau dkk,2020) dan sementara itu untuk menempatkan karyawan dengan bidang pekerjaan yang tepat membutukan data dari bidang pekerjaan yang sudah ada berupa kriteria yang sudah ada pada masing masing bidang, untuk itu menurut penulis metode Case Based Reasoning merupakan pilihan yang tepat untuk menentukan penempatan karyawan dengan bidang yang tepat.

Gambaran diatas menjadi pertimbangan penulis dalam membuat judul sistem pakar penentuan penempatan karyawan terhadap bidang pekerjaan berbasis web dengan metode case based reasoning studi kasus CV.Mitra Tehnik ini. Sebagai upaya dalam memilah dan mencocokan karyawan dengan bidang melalui sebuah komputer, Sistem pakar ini dibuat untuk membantu perusahaan dalam memaksimalkan kinerja karyawan dengan cara memilihkan bidang yang cocok untuk karyawan tersebut, Untuk menentukan cocoknya karyawan dengan bidang yang ada, perusahaan melakukan penentuan berdasarkan syarat dan kriteria yang ada pada suatu bidang yang nantinya para karyawan akan disuruh memilih beberapa kriteria yang ada sebagai acuan perusahaan dalam menentukan kecocokan melalui sistem pakar.

Bebarapa penelitian terkait yang digunakan untuk mendukung penelitian ini antara lain: Jurnal penelitian pertama yaitu "Penerapan Case Based Reasoning (Cbr) Pada Sistem Pakar Diagnosa Penyakit Otitis Media Supuratif Kronis 


\section{Journal of Information Technology Ampera \\ Vol. 2, No. 2, August 2021 e-ISSN: 2774-2121}

https://journal-computing.org/index.php/journal-ita/index

(Omsk) Pada Orang Dewasa" yang ditulis oleh Gita triswardani dan Nelly astuti hasibuan. Pada jurnal tersebut membahas tentang penerapan metode Case Based Reasoning dalam mendiagnosis penyakit otitis menggunakan media supuratif kronis.dalam analisa dan pembahasan jurnal ini terdapat penjelasan cara melakukan diagnosa, yaitu dengan cara mengadaptasi solusi-solusi yang terdapat pada kasus-kasus sebelumnya yang mirip dengan kasus-kasus sebelumnya sebagai perbandingan untuk kasus yang baru, setelah itu melakukan tes kemiripan (similarity) yang merupakan salah satu langkah dalam metode Case Based Reasoning [3].

Jurnal penelitian selanjutnya yang terkait adalah "Rancang Bangun Sistem Pakar Pendiagnosa Penyakit Paru-Paru Menggunakan Metode Case Based Reasoning" yang ditulis oleh Diki andita kusuma dan Chairani. Dalam jurnal penelititan ini terdapat contoh analisis sistem dalam melakukan diagnosis, mulai dari bagaimana tahap pencarian kemiripan kasus (retrieve). Tahap reuse yaitu penggunaan kembali kasus lama untuk kasus baru yang memiliki bobot kemiripan yang paling relevan, sehingga menghasilkan solusi untuk masalah baru. Tahap revise yaitu tahap peninjauan kembali kasus dan solusi yang diberikan apabila proses retrieve tidak dapat memberikan hasil diagnosis yang tepat. Tahap retain yaitu ketika proses revise selesai dan sudah benar-benar ditemukan solusi yang tepat dan kemudian kasus disimpan untuk menyelesaikan masalah yang memiliki permasalahan yang sama [4].

Jurnal penelitian selanjutnya adalah "Sistem Pakar Diagnosa Penyakit Pencernaan Manusia Menggunakan Metode Case Based Reasoning" yang ditulis oleh Ernawati. Pada jurnal penelitian ini sistem memiliki beberapa kriteria yang digunakan untuk menentukan penyakit pada pencernaan manusia, di setiap kriteria terdapat relasi yang salaing terhubung dengan kasus-kasus yang sudah ada sebelumnya serta bobot masing-masing sesuai penyakit yang ada [5]. Jurnal penelitian selanjutnya yang terkait adalah "Sistem Pakar dalam Mendeteksi Kerusakan Laptop dengan Metode Case Based Reasoning" yang ditulis oleh Harif A Rahman. Penelitian ini membahas tentang pembangunan sistem pakar dalam melakukan perhitungan menggunakan metode Case Based Reasoning (CBR), objek yang di teliti oleh pada penelitian ini adalah data gejalagejala yang terdapat pada beberapa jenis kerusakan laptop. Penelitian ini menggunakan Sistem Pakar yang berfungsi sebagai pengganti pakar sebagai media konsultasi [6]. Jurnal terkait selanjutnya adalah "Sistem Deteksi Awal Penyakit TBC dengan Metode CBR' yang ditulis oleh Arnes yuli vandika dan Ahmad cucus. penelitian ini mencoba untuk membuat alternatif yang dapat di gunakan untuk deteksi awal penyakit TBC. Case Based Reasoning telah banyak di terapkan dalam berbagai kecerdasan buatan, baik berbentuk sistem pakar 
maupun sistem penujang keputusan yang membantu para pembuat keputusan untuk mengambil keputusan secara tepat. Case Based Reasoning bekerja dengan cara mempelajari kasus-kasus terdahulu yang dikumpulkan dalam sebuah General Knowledge yang nantinya akan dikomparasi dengan kasus yang baru, Case Based Reasoning memiliki empat tahap yaitu Retrieve, Reuse, Revise dan Retain, cara ini sangat ampuh untuk membuat sistem pakar yang dibuat menjadi mesin pembelajar, yang secara otomatis akan menambah atau merivisi pengetahuan secara otomatis kedalam general knowledge [7].

Jurnal terkait selanjutnya adalah "Sistem Pakar Kerusakan Sepeda Motor Non Matic dengan Metode Case Based Reasoning (CBR) yang di tulis oleh Ali akbar malau dkk. Jurnal penelitian ini membahas tentang sistem pakar untuk mendiagnosa kerusakan sepeda motor, dibuat menggunakan metode case base reasoning (CBR) dan algorimat K-NN metode case base reasoning merupakan proses pelacak sedangkan algoritma K-NN merupakan nilai kepastian yang telah diberikan oleh para ahli untuk membuktikan suatu fakta yang ada. Hasil aplikasi menggunakan visual basic yang didalam berupa menjadi dua level yaitu pakar dan user. Pakar untuk mempresentasikan pengetahuan, sedangkan user untuk mendiagnosa bagi para pengguna motor yang mengalami kerusakan [2]

Jurnal terkait selanjutnya adalah "Case Based Reasoning untuk Diagnosis Penyakit Jantung Menggunakan Minkowski Distance" yang ditulis oleh Eka wahyudi dan Novi indi pradasari. Jurnal ini membahas tentang penelitian sistem CBR untuk diagnosa penyakit jantung, Proses diagnosis dilakukan dengan cara memasukkan kasus baru yang berisi fitur-fitur yang akan didiagnosis ke dalam sistem, kemudian melakukan proses perhitungan nilai similaritas antara kasus baru dengan basis kasus minkowski distance[8].

\section{METODE PENELITIAN}

\section{A. Studi Literatur.Teknik}

Pengumpulan data dengan cara mengumpulkan literatur, jurnal, paper dan sumber lain yang berkaitan dengan judul penelitian.

\section{B. Pengumpulan Data Observasi}

Teknik pengumpulan data dengan mengadakan penelitian dan peninjauan langsung terhadap permasalahan yang diambil.

\section{Tahap Pembuatan Perangkat Lunak}

Teknik analisis data dalam pembuatan perangkat lunak menggunakan metode waterfall, yang meliputi beberapa proses yaitu sebagai berikut : 


\section{Journal of Information Technology Ampera \\ Vol. 2, No. 2, August 2021 e-ISSN: 2774-2121}

https://journal-computing.org/index.php/journal-ita/index

a. System Engineering.

Tahap menganalisis kebutuhan dari keseluruhan sistem yang akan diaplikasikan ke dalam bentuk software agar elemen-elemen lain seperti hardware dan database dapat berinteraksi.

b. Analisys.

Tahap menganalisis kebutuhan yang difokuskan pada perangkat lunak.

c. Design.

Tahap menerjemahkan kebutuhan-kebutuhan yang ada kedalam bentuk diagram sebelum dilakukan coding.

\section{d. Coding.}

Tahap implementasi dari tahap desain dengan menerjemahkan desain kedalam bentuk yang dapat dimengerti oleh komputer, yaitu bahasa pemrograman.

\section{e. Testing.}

Tahap pengujian terhadap perangkat lunak yang dibangun agar sesuai dengan kebutuhan yang telah didefinisikan sebelumnya.

\section{f. Maintenance.}

Tahap pemeliharaan dan pengembangan perangkat lunak dengan menambahkan fitur-fitur yang belum ada pada program tersebut.

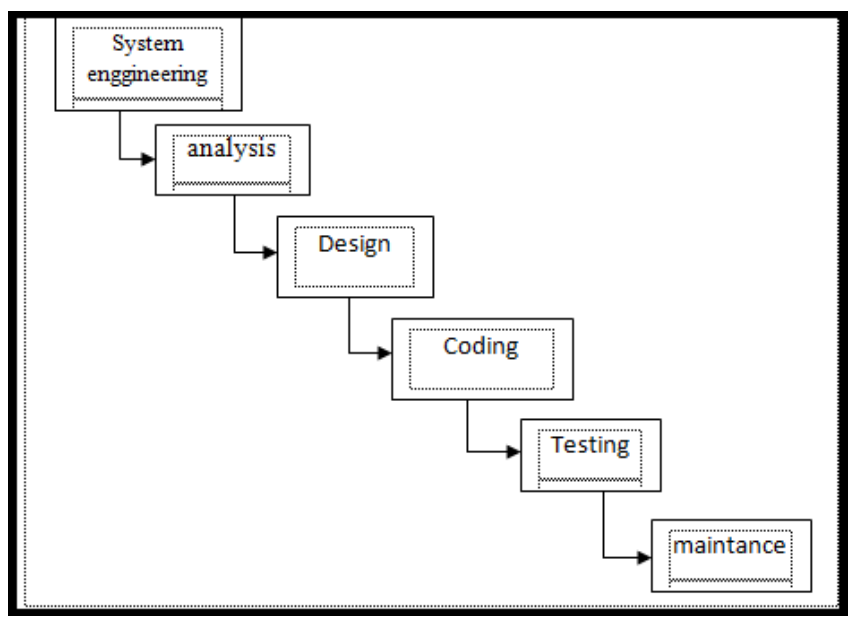

Gambar 1 Tahapan metode waterfall [8] 


\subsection{Landasan Teori}

\section{A. Sistem Pakar}

Suatu sistem pakar merupakan paket perangkat lunak atau pakar program komputer yang ditujukan sebagai penyedia nasihat dan sarana bantu dalam memecahkan masalah di bidang-bidang spesisalisasi tertentu seperti sains, perekayasaan, matematika, kedokteran, pendidikan, dan sebagainya [2]. Jadi dapat disimpulan bahwa sistem pakar merupakan sebuah program komputer yang mencoba meniru atau mensimulasikan pengetahuan (knowledge) dan keterampilan (skill) dari seorang yang ahli pada suatu hal.

\section{B. Case Based Reasoning}

Case Based Reasoning (CBR) adalah cara penyelesaian permasalahan baru dengan cara mempergunakan kembali pengetahuan paling relevan yang telah dimiliki saat ini yang selanjutnya melakukan proses adaptasi terhadap pengetahuan tersebut untuk menyesuaikan dengan permasalahan baru [10]. Ilustrasi dari proses mendapatkan solusi case based reasoning dapat dilihat pada Gambar 2.

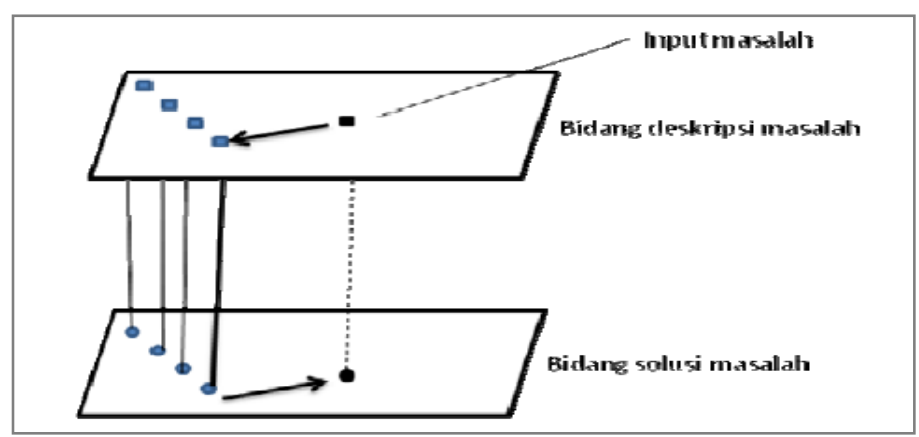

Gambar 2 Pencocokan Kasus Pada metode CBR

Rumus metode Cased Based Reasoning [4]:

$$
\text { similarity }=\frac{\left(S_{1} x W_{1}\right)+\left(S_{2} x W_{2}\right)+\cdots+\left(S_{n} x W_{n}\right)}{W_{1}+W_{2}+\cdots+W_{n}}
$$

Keterangan :

$\mathrm{S}=$ Similarity (nilai kemiripan) yaitu 1 (sama) dan $\mathrm{O}$ (beda) 
W= Bobot yang diberikan pada kriteria

$\mathrm{n}=$ Jumlah kriteria dalam setiap kasus

\section{HASIL DAN PEMBAHASAN}

Hasil dari penelitian yang telah dibuat adalah aplikasi web sistem pakar yang dapat menentukan penempatan karyawan terhadap bidang pekerjaan pada CV.Mitra Tehnik. Aplikasi ini dapat melaksanakan tugasnya berdasarkan pengetahuan yang terdapat di dalamnya seperti yang dilakukan manusia. Untuk itu agar aplikasi sistem pakar yang dikembangkan dapat mempunyai kecerdasan maka harus diberi suatu pengetahuan dan penalaran dari pengetahuan yang sudah didapat dalam menentukan kesimpulan layaknya seorang pakar.

\subsection{Analisa Data}

Tahap analisa data merupakan tahap dalam pengembangan sebuah sistem, karena pada tahap ini dilakukan evaluasi kinerja, identifikasi masalah, rancangan sistem dan langkah-langkah yang dibutuhkan untuk perancangan yang diinginkan sampai pada analisis yang diharapkan.Perancangan pada analisa data ini terdiri dari analisa data kerusakan, data kriteria, dan data solusi. Hal tersebut akan dijelaskan pada uraian dibawah ini :

\section{Data Bagian Perusahaan}

Masalah yang dibahas dalam penelitian ini adalah tentang bagian yang membutuhkan pekerja pada CV.Mitra Tehnik. Dari hasil wawancara yang dilakukan penulis kepada perusahaan didapatkan kejelasan tentang macammacam bagian yang ada pada perusahaan. Berikut adalah macam-macam bagian tersebut:

Tabel 1. Bagian Pekerjaan

\begin{tabular}{|c|c|c|}
\hline No & Kode bagian & Bagian \\
\hline 1 & D001 & Personalia \\
\hline 2 & D002 & Arsitektural \\
\hline 3 & D003 & Elektrikal \\
\hline 4 & D004 & Mekanikal \\
\hline 5 & D005 & Keuangan \\
\hline
\end{tabular}




\begin{tabular}{|c|c|c|}
\hline 6 & D006 & Operasional \\
\hline
\end{tabular}

\section{Data Kriteria}

Pengumpulan data dilakukan untuk memperoleh informasi data bagian pekerjaan dan kriteria beserta relasi antar data tersebut. Data diperoleh dari hasil wawancara dengan seorang kepada bagian dari perusahaan CV.Mitra Tehnik dan studi literatur. Berikut tabel basis pengetahuan yang akan menjelaskan informasi tentang bagian yang ada pada perusahaan dan kriteria yang ada pada bagian tesebut.

Tabel 2. Basis Pengetahuan

\begin{tabular}{|c|c|c|c|}
\hline $\mathrm{No}$ & Bagian & Kriteria & Bobot \\
\hline 1 & Personalia & $\begin{array}{ll}\text { - } & \text { Suka bekerja di dalam ruangan } \\
\text { - } & \text { Pandai mengingat } \\
\text { - } & \text { Mempunyai jiwa sosialisai } \\
\text { - } & \text { Mempunyai kemampuan dalam } \\
\text { - } & \text { negosiasi } \\
\end{array}$ & $\begin{array}{l}5 \\
3 \\
5 \\
5\end{array}$ \\
\hline 2 & Arsitektural & $\begin{array}{ll}\text { - } & \text { Kreatif dan inovatif } \\
\text { - } & \text { Pandai mengatur } \\
\text { - } & \text { Pandai berhitung } \\
\text { - } & \text { Pandai menggunakan komputer }\end{array}$ & $\begin{array}{l}5 \\
3 \\
1 \\
1\end{array}$ \\
\hline 3 & Elektrikal & $\begin{array}{ll}\text { - } & \text { Memiliki kemampuan dalam hal } \\
& \text { kelistrikan } \\
\text { - } & \text { Teliti } \\
\text { - } & \text { Mampu mengoperasikan mesin } \\
\text { - } & \text { Kreatif dan Inovatif } \\
\text { - } & \text { Suka bekerja di lapangan } \\
\end{array}$ & $\begin{array}{l}5 \\
5 \\
5 \\
3 \\
1 \\
3\end{array}$ \\
\hline 4 & Mekanikal & $\begin{array}{l}\text { - } \text { Mampu mengoperasikan mesin } \\
\text { - } \quad \text { Suka bekerja di lapangan } \\
\text { - } \text { Memiliki kemampuan dalam hal } \\
\text { - } \quad \text { Kelistrikan } \\
\text { - Kreatif dan inovatif }\end{array}$ & $\begin{array}{l}5 \\
5 \\
1 \\
3\end{array}$ \\
\hline 5 & Keungan & $\begin{array}{ll}\text { - } & \text { Pandai berhitung } \\
\text { - } & \text { Teliti } \\
\text { - } & \text { Konsisten }\end{array}$ & $\begin{array}{l}5 \\
5 \\
3 \\
5\end{array}$ \\
\hline
\end{tabular}




\section{Journal of Information Technology Ampera}

Vol. 2, No. 2, August 2021 e-ISSN: 2774-2121

https://journal-computing.org/index.php/journal-ita/index

\begin{tabular}{|c|c|c|c|}
\hline & & $\begin{array}{l}\text { - Suka bekerja di dalam ruangan } \\
\text { - } \quad \text { Pandai menggunakan komputer }\end{array}$ & 3 \\
\hline 6 & Operasional & $\begin{array}{ll}\text { - } & \text { Pandai mengatur } \\
\text { - } & \text { Mempunyai jiwa sosialisasi } \\
\text { - } & \text { Mempunyai kemampuan dalam } \\
& \text { negosiasi } \\
\text { - } & \text { Suka bekerja di dalam ruangan } \\
\text { - } & \text { Pandai menggunakan komputer }\end{array}$ & $\begin{array}{l}5 \\
5 \\
3\end{array}$ \\
\hline
\end{tabular}

\subsection{Pembahasan}

Pembahasan dari hasil penelitian meliputi implementasi sistem pakar penentuan penempatan karyawan tehadap bidang pekerjaan berbasis web dengan metode case based reasoning studi kasus CV. Mitra Tehnik adalah sebagai berikut:

1. Halaman Login Sistem

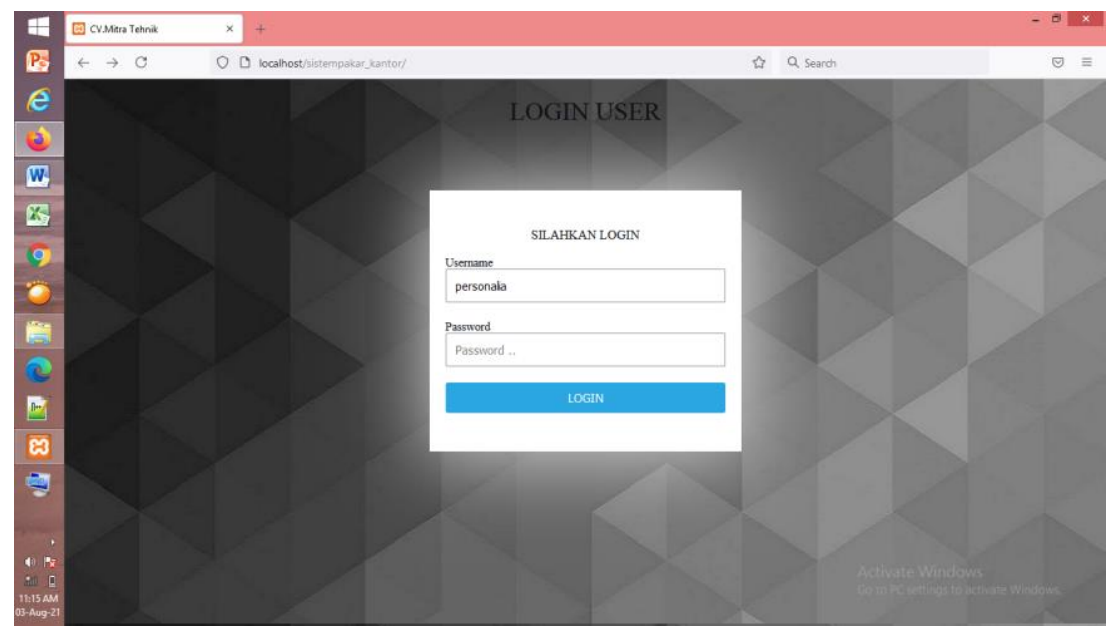

Gambar 3 Halaman login sistem

\section{Halaman Personalia}

Halaman personalia akan menampilkan hasil dari proses perhitungan CBR yang telah dilakukan sistem. Halaman personalia dapat di lihat pada Gambar 4 berikut: 


\section{Journal of Information Technology Ampera}

Vol. 2, No. 2, August 2021 e-ISSN: 2774-2121

https://journal-computing.org/index.php/journal-ita/index

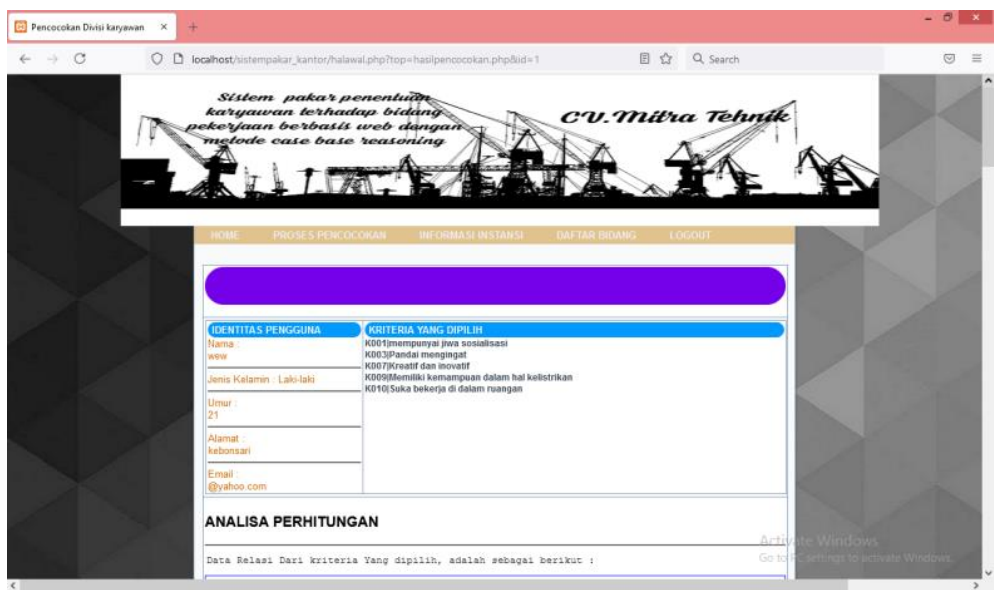

Gambar 4 Halaman hasil

Pada halaman ini proses perhitungan metode $C B R$ dilakukan oleh sistem. Contoh penyelesaian kasus baru dengan perhitungan metode $C B R$ secara manual dapat di lihat pada penjelasan di bawah ini :

Tabel 3 Tabel kasus baru

\begin{tabular}{|c|c|c|}
\hline No & Kode Kriteria & Nama Kriteria \\
\hline 1 & K002 & Teliti \\
\hline 2 & K004 & Kandai menggunakan konmputer \\
\hline 3 & K007 & Memiliki kemampuan dalam hal kelistrikan \\
\hline 4 & K009 & \\
\hline
\end{tabular}

Pada Tabel 3 kasus baru masih belum memberikan solusi karena belum terindentifikasi oleh sistem.

Tabel 4. Tabel Kasus lama 1 (Bidang personalia)

\begin{tabular}{|c|c|l|c|}
\hline No & Kode Kriteria & Nama Kriteria & Bobot \\
\hline 1 & K010 & Suka bekerja di dalam ruangan & 5 \\
\hline 2 & K003 & Pandai mengingat & 3 \\
\hline 3 & K001 & Mempunyai jiwa sosialisa & 5 \\
\hline 4 & K006 & $\begin{array}{l}\text { Mempunyai kemampuan dalam } \\
\text { negosiasi }\end{array}$ & 5 \\
\hline 5 & K004 & Pandai menggunakan komputer & 3 \\
\hline
\end{tabular}




\section{Journal of Information Technology Ampera}

Vol. 2, No. 2, August 2021 e-ISSN: 2774-2121

https://journal-computing.org/index.php/journal-ita/index

Tabel 5. Tabel Kasus lama 2 (Bidang arsitektural)

\begin{tabular}{|c|c|l|c|}
\hline No & Kode Kriteria & Nama Kriteria & Bobot \\
\hline 1 & K007 & Kreatif dan inovatif & 5 \\
\hline 2 & K013 & Pandai mengatur & 3 \\
\hline 3 & K005 & Pandai berhitung & 1 \\
\hline 4 & K004 & Pandai menggunakan komputer & 1 \\
\hline
\end{tabular}

Tabel 6. Tabel kasus lama 3 (Bidang elektrikal)

\begin{tabular}{|c|c|l|c|}
\hline No & Kode Kriteria & Nama Kriteria & Bobot \\
\hline 1 & KO09 & $\begin{array}{l}\text { Memiliki kemampuan dalam hal } \\
\text { kelistrikan }\end{array}$ & 5 \\
\hline 2 & K002 & Teliti & 5 \\
\hline
\end{tabular}

Tabel 6. Tabel kasus lama 3 (Bidang elektrikal) (Lanjutan)

\begin{tabular}{|c|c|l|c|}
\hline No & Kode Kriteria & Nama Kriteria & Bobot \\
\hline 3 & K008 & Mampu mengoperasikan mesin & 3 \\
\hline 4 & K007 & Kreatif dan inovatif & 1 \\
\hline 5 & K012 & Suka bekerja di lapangan & 3 \\
\hline
\end{tabular}

- Proses retrive

Disini dilakukan proses pencocokan kriteria kasus baru atau mencari kemiripan kriteria antara kasus lama dan kasus baru seperti pada langkah dibawah ini :

Tabel 7. Tabel Pencocokan 1 ( Bagian Personalia)

\begin{tabular}{|c|c|}
\hline Kriteria kasus Baru & Kriteria kasus lama \\
\hline K002 (0) & K010 (5) \\
\hline K004 (3) & K003 (3) \\
\hline K007 (0) & K001 (5) \\
\hline K009 (0) & K006 (5) \\
\hline & K004 (3) \\
\hline
\end{tabular}

Tabel 8. Tabel Pencocokan 2 ( Bagian Arsitektural)

\begin{tabular}{l|l} 
Kriteria kasus Baru & Kriteria kasus lama
\end{tabular} 
Journal of Information Technology Ampera

Vol. 2, No. 2, August 2021 e-ISSN: 2774-2121

https://journal-computing.org/index.php/journal-ita/index

\begin{tabular}{|l|l|}
\hline K002 (0) & K007 (5) \\
\hline K004 (1) & K013 (3) \\
\hline K007 (5) & K005 (1) \\
\hline K009 (0) & K004 (1) \\
\hline
\end{tabular}

Tabel 9. Tabel Pencocokan 3 ( Bagian Elektrikal)

\begin{tabular}{|l|l|}
\hline Kriteria kasus Baru & Kriteria kasus lama \\
\hline K002 (5) & K009 (5) \\
\hline K004 (0) & K002 (5) \\
\hline K007 (1) & K008 (3) \\
\hline K009 (5) & K007 (1) \\
\hline & K012 (3) \\
\hline
\end{tabular}

- Proses reuse

Pada proses ini dilakukan perhitungan kemiripan antara kasus lama dengan kasus yang baru yang mengacu pada Rumus 2.1. perhitungan yang dilakukan yaitu :

Similarity $(\mathrm{X}, \mathrm{D} 01)$ :

$$
\begin{aligned}
& \frac{[(0 * 5)+(0 * 3)+(0 * 5)+(0 * 5)+(1 * 3)]}{5+3+5+5+3} \\
& =0,1428571429(14 \%)
\end{aligned}
$$

Similarity (X, D02) :

$$
\begin{aligned}
& \frac{[(1 * 5)+(0 * 3)+(0 * 1)+(1 * 1)]}{5+3+1+1} \\
& =0,6(60 \%)
\end{aligned}
$$

Similarity $(\mathrm{X}, \mathrm{DO3})$ : 


\section{Journal of Information Technology Ampera}

Vol. 2, No. 2, August 2021 e-ISSN: 2774-2121

https://journal-computing.org/index.php/journal-ita/index

$$
\begin{aligned}
& \frac{[(1 * 5)+(1 * 5)+(0 * 3)+(1 * 1)+(0 * 3)]}{5+5+3+1+3} \\
& =0,6470588235(65 \%)
\end{aligned}
$$

\section{- Proses revise}

Proses revise dilakukan apabila nilai kepercayaan yang dihasilkan pada proses reuse memiliki tingkat kepercayaan yang rendah. Pada kasus diatas nilai kepercayaan pada kasus baru yaitu 65\% artinya nilanya cukup mirip dengan kasus lama karena menurut hasil wawancara yang telah dilakukan pada CV.Mitra Tehnik, karyawan baru setidaknya harus memiliki lebih dari setengah kemampuan bidang yang dituju. Namun apabila nilai rendah maka proses revise akan dilakukan oleh pakar dengan melihat kasus tersebut.

\section{- Proses retain}

Pada proses ini apabila kasus baru tersebut benar- benar ditemukan solusinya barulah pakar memasukan kasus ini kedalam data pengetahuan untuk digunakan menyelesaikan masalah apabila ada kasus baru lagi yang memiliki ciri atau kriteria yang sama.

\section{Halaman Admin}

Halaman admin dapat dibuka apabila user memiliki hak akses ke halaman admin. Halaman admin dapat di lihat pada Gambar 5 berikut :

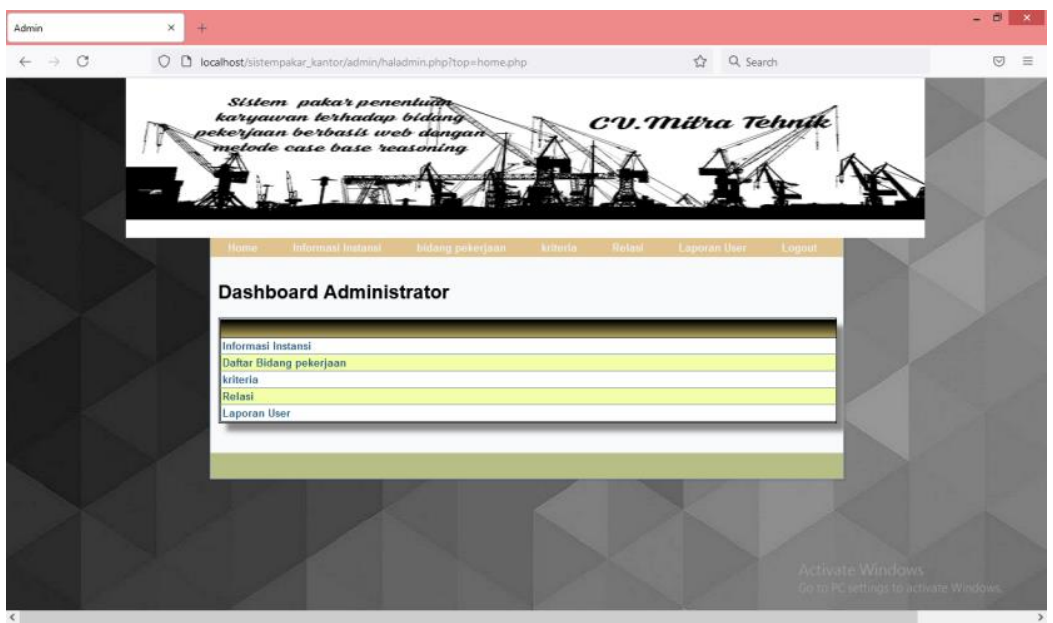

Gambar 5 Halaman awal admin 


\subsection{Hasil Pengujian Sistem}

Sesuai dengan hasil pengujian yang telah dilaksanakan dengan metode pengujian blackbox didapatkan presentase keberhasilan sebesar 100\%, maka sistem pakar untuk menentukan penempatan karyawan terhadap bidang pekerjaan berbasis web studi kasus CV.Mitra Tehnik sudah memenuhi kriteria dalam kinerja maupun fungsi yang diharapkan. Dengan begitu maka sistem pakar untuk menentukan penempatan karyawan tehadap bidang pekerjaan pada berbasis web studi kasus CV.Mitra Tehnik ini dinyatakan layak untuk digunakan.

\section{KESIMPULAN}

Kesimpulan yang di dapat selama melakukan penelitian tugas akhir ini adalah Pada penelitian sistem pakar untuk menentukan penempatan karyawan terhadap bidang pekerjaan pada CV.Mitra Tehnik berbasis web telah berhasil di rancang dan dibuat untuk perusahaan CV.Mitra Tehnik selain itu sistem pakar ini telah berhasil di implementasikan ke dalam sistem untuk digunakan sebagai alat untuk untuk perusahaan dalam menempatkan karyawan baru terhadap bidang pekerjaan yang sesuai dengan keahlian dan sistem telah diuji menggunakan metode blackbox dengan keberhasilan 100\%.

\section{DAFTAR PUSTAKA}

[1] Y.C.M. Mage, D.R Sina and T. Widiastuti, Case Base Reasoning untuk Mendiagnosa Penyakit Anak Menggunakan Metode Block City.JICON, 5(2), 42-27. 2017.

[2] A.A.Malau, R.U. Ginting, R. Sitanggang, and B. Damanik. SISTEM PAKAR DIAGNOSA KERUSAKAN SEPEDA MOTOR NON MATIC DENGAN METODE CASE BASE REASONING (CBR). Jurnal TEKESNOS. 2(1) , 21-26.2020.

[3] G.Triswardani and N.A.Hasibuan, Penerapan Case Based Reasoning (Cbr) Pada Sistem Pakar Diagnosa Penyakit Otitis Media Supuratif Kronis (Omsk) Pada Orang Dewasa, Jurnal Media Informatika Budidarma.Vol.2(2). 3339,2018.

[4] D.A.Kusuma and Chairani. Rancang Bangun Sistem Pakar Pendiagnosa Penyakit Paru-Paru Menggunakan Metode Case Based Reasoning. Jurnal Infotel. 6(2), 57-62. 2014.

[5] Ernawati. Sistem Pakar Diagnosa Penyakit Pencernaan Manusia Menggunakan Metode Case Based Reasoning. Jurnal SISTEMASI, 6(2), 35-44. 2017 
[6] H.A.Rahman. Sistem Pakar dalam Mendeteksi Kerusakan Laptop dengan Metode Case Based Reasoning. Jurnal Sistim Informasi dan Teknologi, 2(3), 71-76. 2020.

[7] A.Y. Vandika, and A. Cucus. Sistem Deteksi Awal Penyakit TBC Dengan Metode CBR. Jurnal Informatika, 17(2), 54-60. 2017.

[10] E.Wahyudi and N.I. Pradasari. Case Based Reasoning Untuk Diagnosa Penyakit Jantung Menggunakan Metode Minowski Distance. INTECOMS, 1 (1),119-123. 2018.

[9] R.S Pressman."Rekayasa Perangkat Lunak: Pendekatan Praktisi Buku I". Andi ed, Yokyakarta .2015.

[10] I.M.Prakoso, W.Anggraeni and A.Mukhlason. Penerapan Case- Based Reasoning pada sistem cerdas untuk pendeteksian dan penanganan dini penyakit sapi . Jurnal Teknik ITS. 1(1), A-351-A-356. 2012. 